\title{
Vajilla de madera de época romana en Hispania: caracterización, contexto y tipología
}

\section{Wooden tableware in Hispania: characterization, context and typology}

\author{
JAVIER SALIDO DOMÍNGUEZ \\ Universidad Autónoma de Madrid. Departamento de Prehistoria y Arqueología \\ C/ Francisco Tomás y Valiente, s/n, E-28049 Cantoblanco (Madrid) \\ javier.salido@uam.es
}

Se expone en este artículo un tema poco analizado desde la perspectiva arqueológica: el uso de la madera para la fabricación de la vajilla romana. Acostumbrados a cuantificar, examinar y reconocer la terra sigillata como la vajilla más frecuente de la mesa romana, y teniendo en cuenta su importancia para la datación, hemos obviado la presencia de otros utensilios y enseres de madera que, si bien no son tan frecuentes en el registro arqueológico, también estaban presentes en la vida cotidiana en época romana.

\section{PALABRAS CLAVE}

VAJILLA, MADERA, POZOS, TERMAS, HISPANIA

This paper analyzes the use of domestic wooden tableware in the Iberian Peninsula during the Roman period, a subject rarely studied from an archaeological perspective. The traditional classification and quantification of terra sigillata as the most common vessels for dining at the Roman table, together with their importance for dating, has led to a lack of knowledge and appreciation of the role of wooden utensils and objects that, although not frequent in the archaeological record, were also common items in everyday life in Roman times.

\section{KEYWORDS}

TABLEWARE, WOOD, WELLS, BATHS, HISPANIA 


\section{Introducción}

La vajilla de mesa de lujo por excelencia en época romana fue realizada fundamentalmente en materiales nobles como la plata. La dignidad de un material de sonido metálico y de apariencia vistosa y fulgurante restó la importancia y la practicidad de otros recipientes y enseres más comunes fabricados en cerámica. A la plata, como material asociado a la aristocracia romana, debemos sumarle el papel que jugó el vidrio para la bebida, elemento esencial de los symposia y banquetes romanos, el cual, por sus cualidades - transparencia, el gusto que ofrece al bebedor y su limpieza-, hizo que ocupara un puesto importante en las mesas romanas de los nobles, aunque pronto se fue popularizando. El uso de la cerámica para la fabricación de la vajilla de mesa, con el progresivo abaratamiento de los costes, provocó que ciertos talleres gozaran de más éxito, inundando los mercados de piezas de diversas formas y tipos, hasta conseguir que la terra sigillata se convirtiera no solo ya en el símbolo de la mesa romana, sino de la propia romanidad.

La terra sigillata constituye el tipo de vajilla mejor conocido desde el punto de vista arqueológico. No cabe duda de que su importancia para fechar contextos estratigráficos ha motivado que, en numerosas ocasiones, este fósil director haya sido el objeto de atención de numerosos congresos, seminarios y encuentros científicos. Pero la trascendencia que tuvo la vajilla cerámica no nos debe hacer obviar la presencia de otros enseres que también fueron empleados en la mesa en época romana. Precisamente en este artículo pretendemos poner el énfasis en el estudio de esos objetos que desafortunadamente han pasado más desapercibidos y que, por diversas circunstancias, apenas han dejado huella en el registro arqueológico, un material que nos acerca a la vida cotidiana de ciertas poblaciones que no son tan perceptibles y que esta publicación pretende visibilizar.

\section{El uso de la madera para la elaboración de objetos en Hispania}

Los primeros estudios que se aproximaron al estudio de la vajilla lignaria de época romana se basaron principalmente en la información aportada por las fuentes clásicas y la etnografía (Balil, 1980; De Blas Cortina, 1995). Afortunadamente, en las últimas décadas se han podido documentar restos materiales en diferentes contextos hispanorromanos que nos permiten abordar un análisis más detallado sobre la tipología, materiales y técnicas de fabricación de las piezas recuperadas.

Los problemas de conservación de la madera en contexto arqueológico explican la escasez de testimonios arqueológicos localizados hasta el momento en la península ibérica. Además de algunos fragmentos de utensilios, herramientas y objetos fabricados en época prerromana (García y Bellido, 1956: 165; Carrión y Rosser, 2010; Martín-Seijo y Carrión, 2012: 136-139), contamos con información sobre la recuperación de piezas de madera 
datadas en época romana, además de la madera utilizada como material de construcción, analizadas en una monografía que hemos editado recientemente (Morillo et al., 2019). Entre los materiales, además de los que indicaremos en el catálogo analítico, podemos destacar instrumentos de uso cotidiano, elaborados con Quercus sp., como las asas localizadas en Castromao, Neixón Grande, el gancho de Coto do Mosteiro y un utensilio de funcionalidad desconocida de Nabás, quizá una caja (Martín-Seijo y Carrión, 2012: tabla 1). Este tipo de madera fue el más empleado también en la mayor parte de los objetos de madera de Gijón, elegido fundamentalmente por su dureza, aunque estos son de época tardoantigua (Fernández Ochoa et al., 2015, 2016; Fernández Ochoa y Orejas, 2019). En madera se fabricaron también los útiles reconocidos en Tossal de les Basses (Alicante) (Carrión y Rosser, 2010), además de las herramientas localizadas en varios yacimientos del noroeste peninsular (Martín-Seijo y Carrión, 2012: tabla 3). Menos información disponemos de los fragmentos carbonizados de madera de haya (Fagus sp.) correspondientes a un objeto que fue arrojado y quemado en un vertedero del balneario romano de Archena, del siglo I d. C. (García y Matilla, 2013), aunque desconocemos su funcionalidad. Una cuestión aún pendiente y poco reconocida en el registro arqueológico son las joyas lignarias de ornato personal (Aranegui, 1982: 44, lám. XII, 3 y 4), además de las obras de arte fabricadas en madera (Matterne y Derreumaux, 2008; Costa et al., 2015: 14, figs. 23 y 24; Figueiral et al., 2015) y otro tipo de objetos suntuosos, como esculturas y depósitos votivos reconocidos en otras regiones sometidas al poder de Roma ( $c f$. Vatin, 1972; Bémont, 1993; Hedinger y Leuzinger, 2003: 84-86).

Este tipo de material ha sido documentado en contextos arqueológicos subacuáticos, donde se han recuperado utensilios comunes, pero poco frecuentes en el registro arqueológico, como el martillo de carpintero del pecio romano de Punta de Algas (Más García, 1971), el sello de madera del pecio Cap Negret (Ibiza) (Almagro y Vilar, 1966), los discos de una bomba de achique del pecio de época flavia hundido frente a la Albufereta (Alicante) (Alfaro, 2009: 611), además del material de construcción de los propios barcos (Heinrich, 2019: 171-174).

En relación con las actividades mineras, se ha localizado instrumental conservado en madera (Pérez Macías y Delgado, 2019: 232-237), como las cubetas, gamellas y artesas de madera procedentes de las minas romanas de Riotinto, Aljustrel o Escandia Grande, algunas de las cuales habrían servido como bateas para concentrar el mineral de oro (Domergue, 1990: 127), así como una pala de madera en la mina romana de Arditurri 3 (Oiartzun, País Vasco) (Moreno-Larrazabal, 201 1; Urteaga y Alkaín, 2019: 265).

Respecto a los recipientes, no cabe duda de que los estudios de toneles han centrado una mayor atención entre los especialistas (Marlière, 2002), con estudios muy interesantes sobre su uso en Hispania (Marlière, 2019; Urteaga y Alkaín, 2019). Sin embargo, a pesar de la localización de evidencias de cultura material elaborada en madera, por el momento no se han realizado estudios de conjunto a nivel peninsular que ayuden a dimensionar la importancia de este material en la elaboración de la vajilla de mesa que aquí analizamos. 


\section{La voz de los antiguos: las referencias en las fuentes escritas}

El uso de vajilla de madera no fue ajeno al mundo romano (Balil, 1980; De Blas Cortina, 1995). De hecho, cuando las fuentes clásicas no hacen mención al material, algunos utensilios y recipientes ofrecen dudas sobre su materia prima, pues pudieron ser realizados en madera (Pociña y Pociña, 1992: 557). Sin embargo, la literatura clásica tiende a considerarlo un menaje menor, bien porque se considera que se trata de un precedente de la cerámica y la metálica (Plin. NH 16, 42; Baquílides, Odas y Fragmentos, Encomios, n. 21 ; Tibulo, Elegías, 1, 1) o porque se asocia a un origen foráneo (Ateneo, Banquete de los eruditos, 4).

En el caso concreto de la península ibérica, Estrabón $(3,3,7)$ indica que los cántabros «usan vasos labrados de madera como los celtas». Pero esta imagen estereotipada de oposición romanidad/barbarie no nos debe hacer pensar que estos útiles no formaban parte de la vida cotidiana. Las fuentes clásicas, imbuidas de una carga aristocrática que tiende a enfatizar los materiales nobles como la plata, nos legan algunos comentarios que dejan entrever la cotidianidad de la vajilla lignaria. Marcial $(12,32)$ en uno de sus epigramas insinúa que Vacerra era tan indigente que él mismo talló el cuenco con un material totalmente inadecuado como es la madera de cornejo. Esta especie, que no es fácil de tallar, fue apreciada en la antigüedad por su dureza y solo es adecuada para tacos (Cato Agr. 18, 9) y cuñas (Plin. NH 16, 206) (Pugsley, 2003: 100). Entre la aristocracia romana, los recipientes realizados con madera de haya eran muy apreciados por el propio material, e incluso se podían utilizar para los sacrificios (Ovid. Met. 8, 670; Plin. $N H$ 16, 185). Por su parte, Plinio (NH 16, 35) señala que «la hiedra tiene una asombrosa propiedad para probar la pureza de los vinos: si se hace una vasija con su madera, el vino se filtra y el agua se estanca». Otras referencias dejan entrever el uso de recipientes más ligeros que pudieron realizarse en madera: «En los bordes de la pila se colocan las bandejas con las entradas y los platos más consistentes, mientras que los platos más ligeros pasan de unos comensales a otros flotando en el agua sobre figuras que representan pequeñas naves y aves de todo tipo» (Plin. Ep. 5, 6).

\section{Catálogo y contexto arqueológico}

A continuación, presentamos un catálogo analítico de los fragmentos de material lígneo correspondientes a vajilla de mesa localizados en la península ibérica (fig. 1). No incluimos en este estudio las posibles tapaderas u opercula utilizadas para cerrar recipientes auxiliares destinados a la preparación, servicio, conservación o almacenaje de alimentos sin el uso del fuego, o bien para las botellas empleadas en la mesa u otro tipo de recipientes de cocina. Se han documentado tapaderas de madera de época romana que podrían servir para cubrir recipientes de conservantes de alimentos, como el cierre de madera de época romana elaborado en Buxus sp. localizado en Tossal de les Basses (Alicante) (Carrión y Rosser, 


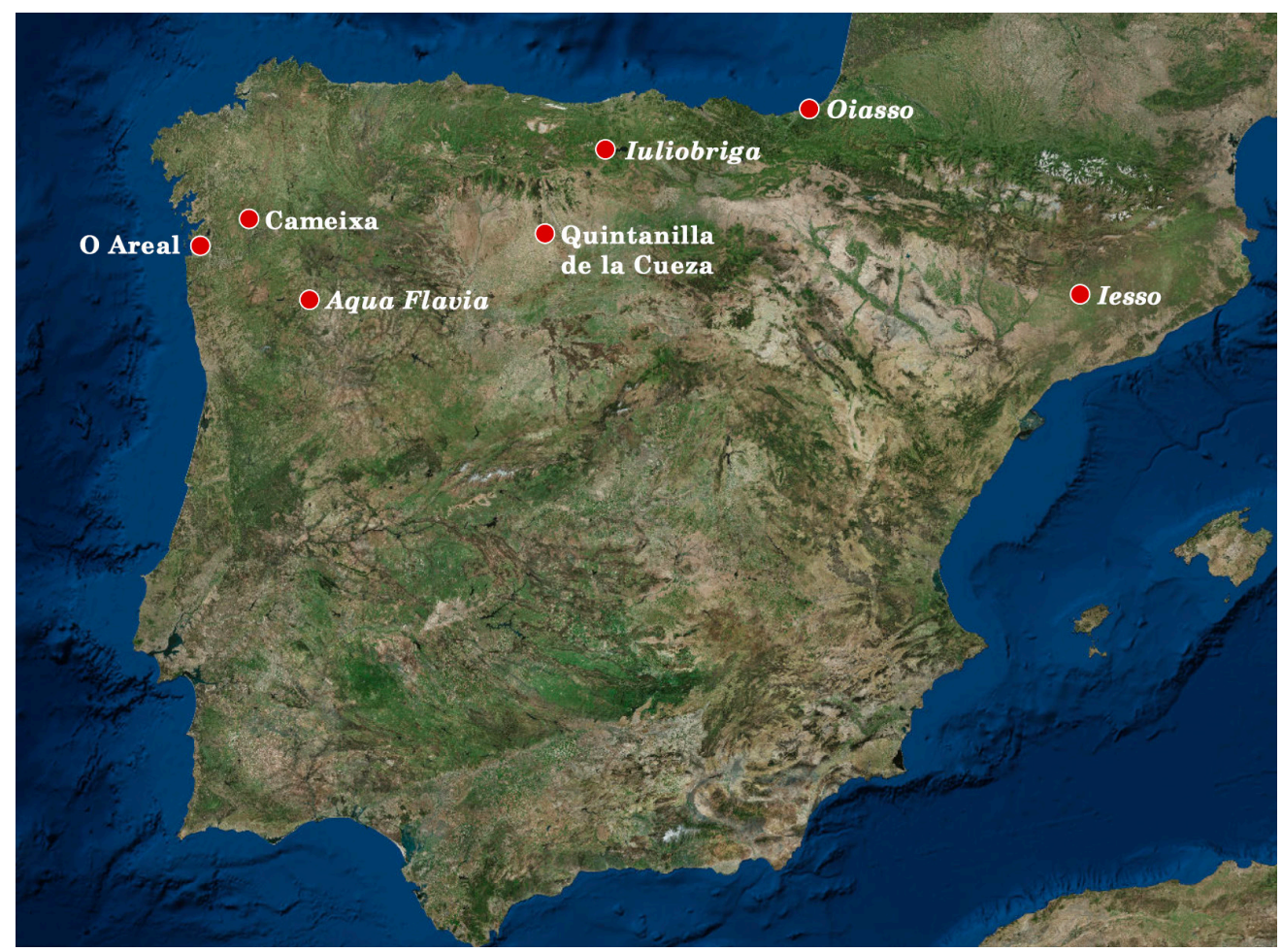

Figura 1. Mapa de dispersión de los hallazgos de vajilla lignaria en Hispania.

2010: tabla 2 y fig. 5), pero es difícil de adscribir exclusivamente a la vajilla de mesa, ya que parece corresponder a utillaje de cocina. Son diferentes a las tapaderas y tapones de corcho, como los hallados entre otros yacimientos en el establecimiento balneario de Chaves (Portugal) (Costa et al., 2015: 9-10), en la «Font dels Lleons» (Tarragona) (Sada, 2004) o en las salinas romanas de O Areal (Vigo), realizados con corcho de alcornoque (Martín-Seijo, 2019: 185). Su considerable tamaño nos permite en ocasiones asociarlos a ánforas como las que transportaba el pecio de San Ferreol (San Pedro del Pinatar, Murcia), datado en el siglo i a. C. (Museo Nacional de Arqueología Subacuática, n. ${ }^{\circ}$ inv. 02093/1).

\section{1. Ámbito castreño}

\section{Castro de Cameixa (Boborás, Orense)}

En el nivel IV del castro de Cameixa (Galicia), se localizaron siete fragmentos de un vaso de madera carbonizado (López Cuevillas y Lorenzo Fernández, 1986: 18-21 y 290). 
Recientemente este nivel IV, reconocido en la campaña de 1945, ha sido fechado en torno a los años 100 a. C. - 120 d. C. (CSIC-742: 1.970 \pm 50 BP) (Carballo y Fábregas, 1991: 255). A pesar de que las muestras fueron recogidas medio siglo antes, desde entonces guardadas y expuestas en una vitrina del Museo Arqueológico de Orense, tal y como señalan Carballo y Fábregas, los resultados obtenidos son coherentes con el material documentado en dicho nivel.

\section{2. Ámbito urbano}

\section{O Areal (Vigo, Pontevedra)}

Recientemente se han dado a conocer de manera parcial algunos objetos de madera recuperados en las salinas romanas de O Areal (Vigo, Pontevedra), fechados entre los siglos III y v d. C. Además de los objetos de madera, de las salinas se han recuperado sandalias de cuero, frutos (Benavides, 2010) y materiales constructivos de madera (Martín-Seijo y Carrión, 2012: 139-140; Castro et al., 2019; Martín-Seijo, 2019). Aunque no se ha publicado ningún estudio de las piezas en detalle, se ha dado a conocer el hallazgo de una bandeja, dos recipientes y un pequeño cuenco, además de tres punzones, una espátula, dos tapones y varios flotadores, entre ellos algunos de red (Martín-Seijo y Carrión, 2012: 139-141, tabla 2; Martín-Seijo, 2019: 185). El cuenco de pequeñas dimensiones fue realizado con madera de fresno (Fraxinus sp.) (fig. 2.1).

\section{Aquae Flaviae (Chaves, Portugal)}

Las campañas de excavación de los años 2008, 2012 y 2013 en el complejo balneario de Aquae Flaviae localizaron la estructura arquitectónica completada derruida y colapsada, que sellaba un conjunto de materiales de gran interés. La cultura material localizada fecha el momento de derrumbe de la techumbre de las termas y su abandono en el último cuarto del siglo Iv d. C. (Carneiro y Lopes, 2014).

Entre los variados utensilios de madera localizados, además de asas, tapaderas y una cuchara, destacan los dieciséis fragmentos de recipientes que no aparecieron completos. Se localizó uno en la denominada piscina A, doce en la B, y otros tres en la cloaca 1, en un conducto y en el castellum aquae, respectivamente. Se empleó mayoritariamente madera dura en la mayor parte de los recipientes, entre los cuales se incluyen varias formas de cuencos, recipientes y dos posibles mitades de cantimploras (ampullae), una de las cuales con una marca tallada en su exterior lateral (Costa et al., 2015: 9-10, figs. 17 y 18). Seis recipientes fueron realizados con madera de Acer sp., en tres se empleó Alnus/Corylus, uno se elaboró con madera de Fraxinus sp., y otros dos corresponden a fragmentos de madera blanda (Pinus pinaster/pinea); solamente en dos piezas no se pudo identificar el tipo de madera (Costa et al., 2015: tabla 3) (fig. 2.3). 

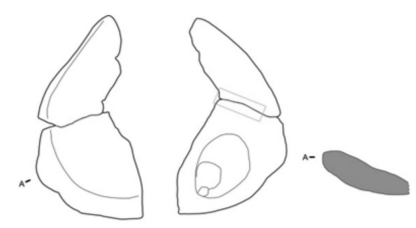

1
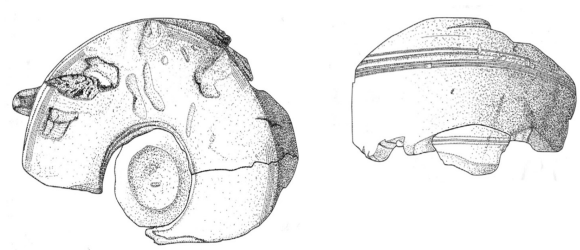

3
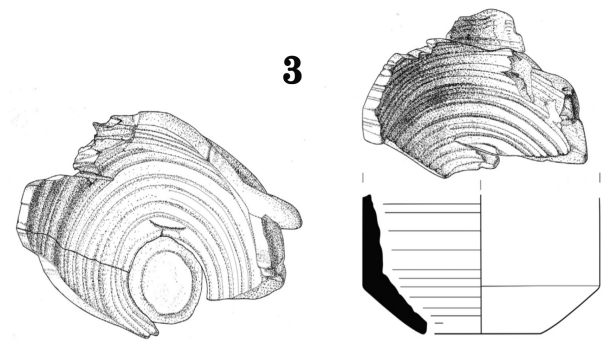

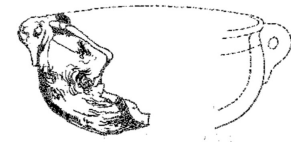

2
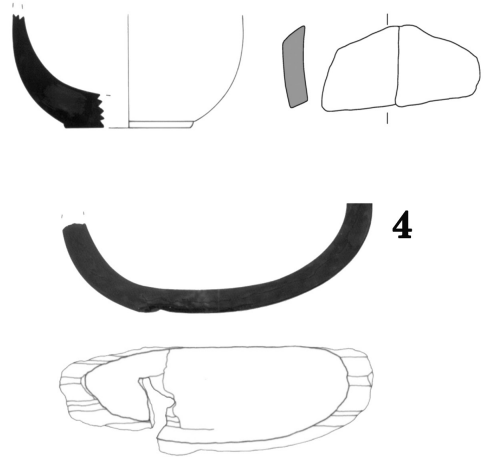

Figura 2. Cuencos de madera hispanorromanos: 1. 0 Areal (Martín-Seijo, 2019: 185); 2. luliobriga (García y Bellido, 1956: fig. 53); 3. Aquae Flaviae (Costa et al., 2015: 9-10, figs. 17 y 18); 4. Oiasso (Urteaga y Alkaín, 2019: figs. 4.14-16).

\section{Iuliobriga (Campoo de Enmedio, Cantabria)}

Las excavaciones arqueológicas realizadas durante 1956 en la ciudad de Iuliobriga (Cantabria) localizaron un pozo o aljibe de 5,10 m de profundidad, colmatado de barro, agua y fragmentos de materiales diversos. En un medio tan adecuado para la preservación de materia orgánica fueron hallados los restos de «tres vasijas de madera» talladas (García y Bellido, 1956: 165-166, fig. 53). Las ilustraciones legadas en la obra de García y Bellido nos permiten determinar que uno corresponde a un vaso y otro a un cuenco con asas perpendiculares a la pared del recipiente y perforadas (fig. 2.2).

\section{Oiasso (Irún)}

Los materiales procedentes del puerto romano de Oiasso (Irún) presentan un estado de conservación excepcional (Urteaga, 2003; Urteaga y Alkaín, 2019). Los fragmentos ligna- 
rios se recuperaron en la excavación del complejo portuario de Tadeo Murgia (Irún). Se localizaron los restos de un muelle, fechado entre los años 70 y 120 d. C., que mantiene su actividad hasta finales del siglo II (Urteaga, 2003). En la intervención se documentaron siete cueros de calzado, un tejido y 18 objetos de madera. En cuanto a la vajilla de mesa, se recuperó un vaso (TMI98, 798) de fondo plano de 3,6 cm de diámetro. Tiene $4 \mathrm{~cm}$ de pared curva en la base, que va haciéndose recta en la parte más alta, con un diámetro en el extremo de 6,6 cm. En la base presenta un pequeño pie plano (Urteaga y Alkaín, 2019: 276, fig. 4.14). El otro vaso (TMI98, 585) se halló fragmentado en dos fracciones de madera torneada. Debía tener aproximadamente 4,8 cm de longitud, 2,2 cm de anchura y $7 \mathrm{~cm}$ de grosor (Urteaga y Alkaín, 2019: 276, fig. 4.15). También se localizó un cuenco hemisférico torneado (TMI98, 292), con perfil semicircular de $9 \mathrm{~cm}$ de diámetro y $8 \mathrm{~cm}$ de grosor y una altura de 4,5 cm (Urteaga y Alkaín, 2019: 276, fig. 4.16) (fig. 2.4).

También se localizaron tres platos de madera de fondo plano (Urteaga y Alkaín, 2019: 277, figs. 4.17-19). El primero (TMI98, 30) presenta pared recta y se conservan dos fragmentos del fondo con parte del alzado del borde. El diámetro aproximado del fondo es de 14-15 cm, con $1 \mathrm{~cm}$ de grosor. El plato TMI98, 203 presenta perfil curvo y borde con labio plano, con un diámetro de $28 \mathrm{~cm}$. La pared tiene un grosor de $1,3 \mathrm{~cm}$, siendo de $1,8 \mathrm{~cm}$ en la base. El plato 3 (TMI98, 209b) presenta perfil curvo y borde con labio plano. Al igual que el plato anterior, la pared tiene un grosor de $1,3 \mathrm{~cm}$.

\section{Iesso (Guissona)}

En el interior del pozo 1 de Iesso (Guissona), fechado a mediados del siglo I d. C., se localizaron restos de varios elementos de vajilla de mesa (Buxó et al., 2004; Pera y Guitart, 2019). Se recuperaron los restos de un cuenco hemisférico de madera de arce (Acer sp.), de base plana y sin borde (Buxó et al., 2004: 227, fig. 39; Pera y Guitart, 2019: 227, fig. 15) (fig. 3). Tiene la

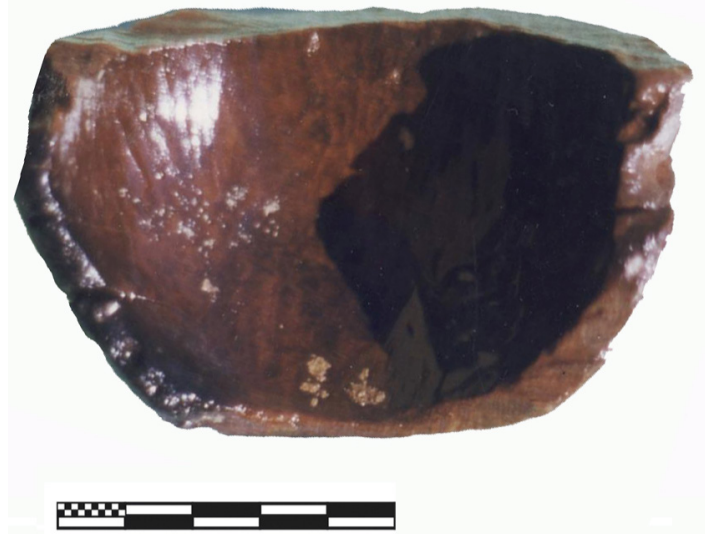

Figura 3. Cuenco de lesso (Guissona). Fuente: Pera y Guitart, 2019: 227, fig. 15. 
superficie exterior pulida, mientras que en el interior presenta marcas del instrumento utilizado para la talla del tronco. Además de este recipiente, que estaba parcialmente quemado, se hallaron varios punzones de madera de boj pulidos, una posible tapadera de pino rojo y forma cónica, dos fragmentos de cestería de madera de sauce, además de elementos de construcción como vigas (Buxó et al., 2004: 227, figs. 40-45). La presencia de terra sigillata hispánica Drag. 37 y Drag. 18 y de cerámica africana de cocina forma Lamb. 9a localizadas en el relleno del pozo permiten fechar la amortización del pozo en torno a mediados del siglo II d. C.

\section{3. Ámbito rural}

\section{Villa romana de Quintanilla de la Cueza (Palencia)}

En la villa romana de Quintanilla de la Cueza (Palencia), se localizó en 1972 una bandeja de madera de forma ovalada de aproximadamente $31 \times 12,5 \mathrm{~cm}$. Aunque se halla fragmentada, se conserva la mayor parte de la pieza. El rebaje interior que forma el cuenco remata en semicírculo en uno de sus lados y de forma recta en el otro; la sección del borde en el primero es semicircular abultada y en el segundo apuntada (Martín Gutiérrez, 2000: 205, lámina 3). Se localizó en la estancia n. ${ }^{\circ} 25$ y, aunque se desconoce la datación concreta de las fases y de la unidad estratigráfica en la que se halló, se ha planteado una cronología para el establecimiento rural entre la segunda mitad del siglo III d. C. y comienzos del IV d. C. (García Guinea, 2000: 276-279) (fig. 4).

\section{La conservación de la vajilla de madera}

Los fragmentos de vajilla de mesa localizados en la península proceden de diferentes contextos que, a nivel general, guardan entre sí unas condiciones ambientales similares que

Figura 4. Bandeja de la villa romana de Quintanilla de la Cueza. Fuente: Martín Gutiérrez, 2000: 205, lámina 3.

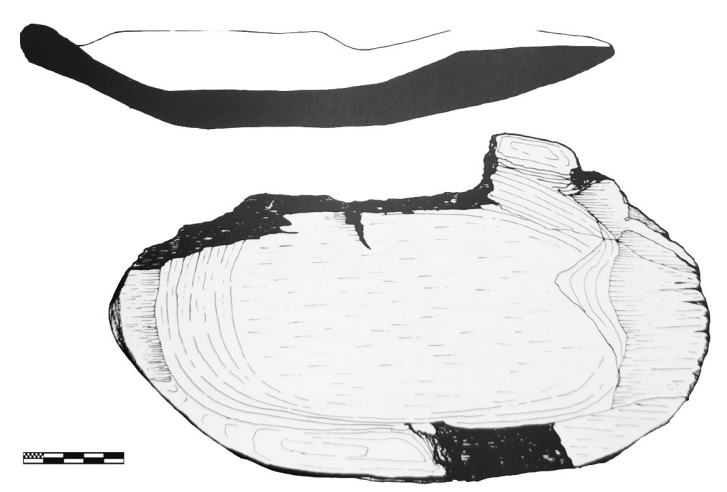


Tabla 1. Fragmentos de vajilla lignaria localizados en Hispania.

\begin{tabular}{|c|c|c|c|c|c|}
\hline No Ámbito & Yacimiento & Cronología & Funcionalidad & Madera & Bibliografía \\
\hline 1 Castreño & $\begin{array}{l}\text { Castro de Cameixa } \\
\text { (Bohorás, Orense) }\end{array}$ & 100 a. C. -120 d. C. & Vaso & $?$ & $\begin{array}{l}\text { Carballo y Fábregas } \\
\text { 1991: } 255\end{array}$ \\
\hline $\begin{array}{l}\text { 2-5 Urbano/salinas } \\
\text { de evaporación }\end{array}$ & $\begin{array}{l}0 \text { Areal (Vigo, } \\
\text { Pontevedra) }\end{array}$ & siglos III y V d.C. & $\begin{array}{l}1 \text { bandeja, } \\
2 \text { recipientes } \\
\text { y un pequeño } \\
\text { cuenco }\end{array}$ & $\begin{array}{l}\text { Fraxinus sp. } \\
\text { (1 cuenco) }\end{array}$ & $\begin{array}{l}\text { Martín-Seijo y Carrión } \\
\text { 2012: 139-141, tabla 2; } \\
\text { Martín-Seijo 2019: } 185 .\end{array}$ \\
\hline 6-21 Urbano/termas & $\begin{array}{l}\text { Aquae Flaviae } \\
\text { (Chaves, Portugal) }\end{array}$ & $\begin{array}{l}\text { Anteriores al } \\
\text { último cuarto } \\
\text { del siglo IV d.C. }\end{array}$ & 16 recipientes & $\begin{array}{l}\text { Acer sp. (6 recipientes), } \\
\text { Alnus/ Corylus (aliso } \\
\text { /avellano) (3 recipientes), } \\
\text { Fraxinus sp. (1 recipiente), } \\
\text { Pinus pinaster / pinea } \\
\text { (2 recipientes) }\end{array}$ & Costa et alii 2015: 9-10. \\
\hline 22-24 Urbano/pozo & $\begin{array}{l}\text { Iuliobriga } \\
\text { (Campoo de } \\
\text { Enmedio, Cantabria) }\end{array}$ & $?$ & 3 recipientes & $?$ & $\begin{array}{l}\text { García y Bellido et alii } \\
\text { 1956: 165-166. }\end{array}$ \\
\hline 25-30 Urbano/puerto & Oiasso (Irún) & $\begin{array}{l}\text { Aprox. } 70 \\
\text { y } 120 \text { d. C. }\end{array}$ & $\begin{array}{l}2 \text { vasos, } 1 \text { cuenco } \\
\text { y tres platos }\end{array}$ & $?$ & Urteaga y Alkaín 2019. \\
\hline 31 Urbano/pozo & lesso (Guissona) & $\begin{array}{l}\text { Mediados del siglo } \\
\text { I d.C.-mediados del } \\
\text { II d. C. }\end{array}$ & 1 cuenco & Acersp. & $\begin{array}{l}\text { Buxó et alii, 2004: } \\
\text { 227, fig. 39; Pera y } \\
\text { Guitart 2019: 227, figs. } \\
15 \text { y } 16\end{array}$ \\
\hline 32 Rural/villa & $\begin{array}{l}\text { Quintanilla de La } \\
\text { Cueza (Palencia) }\end{array}$ & $\begin{array}{l}\text { Segunda mitad } \\
\text { del siglo III d.C. } \\
\text { y comienzos del } \\
\text { IV d.C. }\end{array}$ & 1 bandeja & $?$ & $\begin{array}{l}\text { Martín Gutiérrez 2000: } \\
\text { 205, lámina } 3\end{array}$ \\
\hline
\end{tabular}

han permitido la conservación de los materiales orgánicos perecederos. En el interior de contenedores o estructuras dedicados al uso, almacenaje y acumulación de agua, se ha localizado la mayor parte de la vajilla de mesa de madera.

Los fragmentos de O Areal (Vigo) proceden de unas salinas romanas, mientras que los materiales de Aquae Flaviae (Chaves, Portugal) provienen de un complejo balneario que quedó sellado por el derrumbe de la techumbre. En cambio, los restos materiales de Oiasso (Irún) se localizaron en un área anegada del antiguo complejo portuario de la ciudad, mientras que los objetos del pozo n. ${ }^{\circ} 1$ de Iesso (Guissona) proceden del interior de un pozo colmatado, al igual que los materiales de Iuliobriga. Para la extracción de algunos objetos de madera de Oiasso (Irún) se recuperaron con su base de lodo incluida, mediante planchas de aluminio; posteriormente, terminada la limpieza previa, se guardó todo el material de procedencia orgánica en agua y, para evitar la proliferación de agentes 
de deterioro, se añadieron unas gotas de fungicida al agua de cada bolsa y se almacenaron en unos arcones frigoríficos a una temperatura constante de $+5{ }^{\circ} \mathrm{C}$ (Studer, 2003: 464, láms. VIII-XI y XIV). En el caso de Iesso, la capa freática se encuentra a muy pocos metros de la superficie, de modo que parte de los sedimentos de relleno del pozo habían permanecido en un ambiente anaeróbico húmedo, creándose las condiciones necesarias para la conservación de materiales orgánicos perecederos (Pera y Guitart, 2019: 216). Los trabajos de conservación apropiados realizados desde el momento de su extracción hasta su posterior estudio y almacenaje y, en ocasiones, su exposición al público, mediante la técnica de la liofilización y posterior restitución celular con PEG (polietilenglicol), han permitido proteger y preservar las piezas que, de otro modo, se hubieran perdido para siempre en el registro arqueológico. La aplicación de unas correctas medidas de prevención de los cambios bruscos de humedad relativa, así como de los procesos de rehidratación o de remoldeado, han permitido mantener la materia en un buen estado de conservación (Unger et al., 2001; Benavides, 2010: 352-353).

La localización de estos materiales en ambiente húmedo o anegado es el factor que ha permitido su conservación, pero al mismo tiempo ha provocado importantes cambios del estado del material y problemas en su conservación, debido a la degradación en el proceso de frágil equilibrio al que llegan con el medio que les rodea desde el momento de su deposición. El agua es, en este sentido, un factor importante a tener en cuenta como principal agente tanto del deterioro de las estructuras fibrilares de la madera como de su conservación en ambientes saturados de humedad.

Todos los fragmentos analizados presentan algún tipo de alteración; cambios que no están relacionados con el ataque de microorganismos, sino con alteraciones postdeposicionales. A nivel general, los fragmentos aparecieron húmedos y empapados en agua, con un color oscuro y aspecto de buena conservación. Sin embargo, no cabe duda de que se trata de simple apariencia, ya que solo permanece el esqueleto hueco formado por la lignina, muy frágil, y simplemente con una presión ligera el material es blando y esponjoso (Cronyn, 1990: 250). El adecuado tratamiento preventivo de conservación evitó su mayor deformación y reducción del volumen, e incluso su pulverización, motivada por su extrema fragilidad al entrar en contacto con el exterior (Gea y Dávila, 2019: 59). Las alteraciones fisicoquímicas, mecánicas y biológicas que sufrieron los materiales comportaron un cambio importante en su composición, perceptible en su forma, coloración y peso. Generalmente, las piezas aparecen muy debilitadas, oscurecidas y presentan numerosas fendas y fisuras, como es el caso de las maderas de O Areal (Vigo) que, además, estuvieron expuestas a un gran deterioro porque estuvieron en contacto con los residuos industriales del garaje que durante varias décadas ocupó el solar donde se localizaron. A pesar de encontrarse en las salinas, en un terreno ganado al mar en la actualidad, el nivel de las sales solubles (cloruros y nitratos) del agua que rodeaba a las piezas era bajo, mientras que las sales menos solubles (sulfatos) eran muy elevadas. De hecho, según la información aportada por Benavides (2010: 352), también presentaban un olor intenso a sulfhídrico, aunque en este caso podía deberse a los residuos o degradación bacteriana de la materia orgánica, 
tan presente en el yacimiento. Los ejemplares localizados en Oiasso (Irún) presentaban un mal estado de conservación por el contacto con el medio húmedo circundante. En algunos materiales lignarios aparecidos en el complejo termal de Aquae Flaviae (Chaves, Portugal) se ha podido reconocer incluso la vitrificación de la madera y la aparición de xilófagos (Costa et al., 2015: tabla 2), aunque estas alteraciones no se han podido detectar afortunadamente en los recipientes.

\section{Estudio analítico de la vajilla de mesa lignaria hispanorromana}

El repertorio de vajilla de mesa de Hispania es por el momento limitado, pues solamente se han recuperado 32 fragmentos (tabla 1). Sin embargo, es lo suficientemente importante si se compara con otras regiones que, por sus condiciones edafológicas, permiten una mejor conservación de materiales tan efímeros como la madera (Pugsley, 2003: 103). Todas las piezas recuperadas proceden de contextos de la vertiente septentrional de la península ibérica y, aunque se conocen otros registros conservados en zonas anegadas y ambiente anaeróbico en otras comarcas peninsulares, como hemos señalado en el apartado 2, por el momento ningún fragmento de vajilla lignaria se ha hallado fuera de la franja norte. Por el momento el repertorio más completo de recipientes se ha localizado debajo de la techumbre de las termas romanas de Aquae Flaviae (Chaves, Portugal), mientras que son más variados en cuanto a la tipología los conjuntos recuperados en O Areal (Vigo, Pontevedra) y Oiasso (Irún).

El número limitado de hallazgos y la importancia que tiene otro tipo de vajilla como la cerámica o la realizada en otros materiales más nobles como la plata ha marginado a la lignaria a un segundo plano, siendo considerada como la vajilla propia de las familias más modestas (Rieth, 1940a: 631), sin tener en cuenta que esta convivía con las anteriores en las mesas aristocráticas y que, en ocasiones, su fabricación precisaba de técnicas de profesionales especializados como el uso del torno (Pugsley, 2003: 103).

La vajilla lignaria que se ha conservado y se ha podido recuperar parece producto de la casualidad en el caso del castro de Cameixa (Boborás, Orense), de la villa romana de Quintanilla de la Cueza (Palencia), así como de las salinas romanas de O Areal y del complejo portuario de Tadeo Murgia en Oiasso. No sería descabellado pensar que se trata de la vajilla personal de los trabajadores y habitantes de los diferentes asentamientos. Respecto a los recipientes localizados por debajo del nivel de derrumbe de las termas de Aquae Flaviae (Chaves, Portugal), el hecho de que aparezcan junto a otros materiales como peines, corchos, husillos, etc. nos lleva a pensar que estamos más ante los objetos que se llevaron a las termas cuando estas ya estaban en fase de abandono, que ante útiles que se empleaban durante el propio uso del complejo balneario. Menos dudas ofrece 
el material procedente de los pozos de Iesso (Guissona) e Iuliobriga (Cantabria), que muy posiblemente fue arrojado al interior de dichas estructuras negativas cuando estas ya no se hallaban en uso y eran empleadas como simples vertederos. Este proceso de colmatación se ha podido reconocer también en otras regiones que formaron parte del Imperio romano, aunque fragmentos de vajilla no suelen aparecer con tanta frecuencia. Un buen ejemplo es la vajilla lignaria localizada en los niveles de deposición del interior del pozo n. ${ }^{\circ} 1$ del establecimiento rural romano de Dalton Parlours (Inglaterra), fechada antes del 370 d. C. (Wrathmell, 1990: 271-272), o los materiales recuperados en el pozo de Lattara (Lattes, Francia) (Chabal y Feugère, 2005). En este se encontraron además numerosos restos de cubos de madera y otros contenedores de líquidos, un repertorio muy similar al de la Fábrica de Tabacos de Gijón, aunque la vajilla de este pozo-depósito es de cronología un poco más avanzada (Fernández Ochoa et al., 2015: 141-158, 2016: 122-153; Fernández Ochoa y Orejas, 2019: 150-151).

$\mathrm{Al}$ igual que sucede con la cerámica común y de cocina, los tipos responden fundamentalmente a criterios prácticos y necesidades de uso cotidiano y apenas están sujetos a las modas y los cambios estéticos que afectan a la vajilla fina, de modo que las precisiones cronológicas son relativas. Por lo general, la vajilla lignaria apenas aporta dataciones ni ofrece una información evolutiva de las formas si analizamos contextos cronológicamente dilatados en el tiempo. Pero más allá de precisiones cronológicas, la importancia de su estudio reside en la información indirecta que conlleva sobre los gustos, usos y costumbres culinarias y su dimensión social. Además, aporta nociones de comercio a pequeña y media escala y de las técnicas de fabricación y artesanado con que se elaboró cada producción concreta.

Aunque, a nivel general, los contextos donde han aparecido son pozos colmatados, como en el caso de Iesso (Guissona) e Iuliobriga (Cantabria), o en niveles sellados por el derrumbe como en las termas de Aquae Flaviae (Chaves, Portugal), existen muchos problemas a la hora de datar los materiales de madera aparecidos. En los dos primeros casos, se puede fechar el momento de construcción de los pozos, pero resulta difícil en la mayoría de los casos determinar la cronología exacta de uso de la vajilla encontrada. Del yacimiento cántabro contamos con poca información de la estratigrafía obtenida durante la campaña de excavación de 1956; en cambio, los estudios de Pera y Guitart (2019: 217) sobre la terra sigillata hispánica Drag. 37 y Drag. 18 y de cerámica africana de cocina forma Lamb. 9a encontradas en el relleno del pozo permiten fechar la amortización del pozo en torno a mediados del siglo il d. C. En el caso de las termas de Chaves, el propio derrumbe que sella el nivel donde aparecieron los materiales nos indica que la vajilla aparecida tiene que ser anterior a la caída de la techumbre, es decir, anterior al último cuarto del siglo iv d. C. (Costa et al., 2015).

El otro medio de datación empleado es el carbono-14, obtenido de muestras de materiales orgánicos correspondientes al nivel IV del castro de Cameixa (Boborás, Orense), que ofrece una fecha de los años 100 a. C. - 120 d. C. (Carballo y Fábregas, 1991: 255). A este nivel pertenece la bandeja de madera localizada, aunque conviene señalar que 
estas dataciones son relativas, pues nos ofrecen la fecha de la madera, pero no de la fabricación; además, hay que tener presente que muchas piezas fueron reutilizadas. El uso tardío y la reutilización son procesos que también contribuyen al problema de su datación. No obstante, en el caso de la bandeja de Cameixa, localizada en un nivel del siglo II d. C., podemos adscribir su uso al periodo romano sin temor a equivocarnos. Más problemas ofrecen las dataciones de los materiales de espacios abiertos como el complejo portuario de Oiasso (Irún) y las salinas de O Areal (Vigo, Pontevedra), aunque los materiales asociados se han podido datar en los siglos I-II d. C. y III-V d. C. respectivamente. Para finalizar, la bandeja de la villa romana de Quintanilla de la Cueza (Palencia) carece de una posición estratigráfica clara, pero los estudios de García Guinea (2000: 276-279) abogan por la construcción del establecimiento rural entre la segunda mitad del siglo III d. C. y comienzos del IV d. C.

El repertorio tipológico de los diferentes ejemplares es muy poco variado, pues se documentan básicamente recipientes, interpretados como vasos y cuencos, además de bandejas y platos, que a continuación analizamos de manera detallada.

\subsection{Recipientes: vasos y cuencos (camella lignea)}

Los recipientes constituyen el tipo de vajilla de madera que más atención ha recibido por parte de los especialistas. Sin embargo, el estado fragmentario de las piezas ofrece dificultades para su correcta interpretación o para la identificación de su función exacta. Resulta difícil discernir si los fragmentos conservados corresponden a vasos o cuencos, puesto que en ocasiones la parte conservada no permite reconstruir la sección de la pieza, de modo que en los casos en los que no es posible determinar su tipología, son definidos simplemente como recipientes. Por otro lado, hay que tener presente que los cuencos pueden ser empleados como menaje de cocina (Petr. Satyricon, 135) y vajilla de mesa, además de ser elementos rituales en los sacrificios y ceremonias (Ovid. Fast., 779). Se ha documentado este tipo de vajilla en todos los yacimientos analizados, salvo en la villa romana de Quintanilla de la Cueza (Palencia). Los fragmentos procedentes del castro de Cameixa (Boborás, Orense) y Oiasso (Irún) se han interpretado como vasos debido a su forma cilíndrica, los cuales, junto al que proponemos aquí procedente de Iuliobriga, elevarían a cuatro los ejemplares documentados en la península ibérica. El ejemplar cántabro es muy similar al localizado en el vicus de Tasgetium (Eschenz, Suiza) (Hedinger y Leuzinger, 2003: 111, n. ${ }^{\circ}$ 74). En cambio, la morfología hemisférica de los fragmentos conservados permite definir como cuencos una pieza de O Areal (Vigo, Pontevedra), otra de Oiasso (Irún) y una última procedente de Iesso (Guissona), además de otro ejemplar de Iuliobriga ilustrado en la obra de García y Bellido.

La técnica empleada en la elaboración de estos recipientes se puede reconocer por las marcas del trabajo realizadas durante su preparación. Los recipientes de Iuliobriga (Cantabria) presentan trazas que, según García y Bellido (1956: 165-166), indican que fueron realizados con la técnica del vaciado, al igual que sucede con casi todos los reci- 
pientes procedentes de las termas de Aquae Flaviae (Chaves, Portugal) (Costa et al., 2015: 9-10), para los que se empleó mayoritariamente madera dura. Muy posiblemente fueron tallados por un profesional de la carpintería (tignarius), como se aprecia por el buen trabajo y la técnica empleada. Cuencos tallados con buril se han documentado en yacimientos del norte de Europa, como muestran las marcas practicadas tanto en el interior como en el exterior de los recipientes de Carrickrovaddy Bog (Armagh, Irlanda) (Weatherup, 1978: 42) y el de la Colección del Obispo del Hunterian Museum en Glasgow (Escocia) (Earwood, 1993: 67).

En otros recipientes, en cambio, se aprecian acabados y pulidos que nos informan sobre el uso del torno (tornus) para su elaboración, como en uno de los recipientes del complejo balneario de Aquae Flaviae (Chaves, Portugal) y en los dos vasos y el cuenco localizados en Oiasso (Irún) (Urteaga y Alkaín, 2019: 276). También el cuenco hemisférico del pozo 1 de Iesso (Guissona) presenta la superficie exterior muy pulida, mientras que en el interior presenta marcas del instrumento utilizado para la talla del tronco (Buxó et al., 2004; Pera y Guitart, 2019), lo que podría indicar que fue realizado a torno.

La técnica del torneado exige un trabajo cuidado, solo apto para profesionales (tornatores). Para realizar el cuenco, el carpintero dejaría un núcleo central intacto, que sirve como punto de apoyo y agarre con el torno y que se cortaría al finalizar el trabajo (Ulrich, 2007: 40). La combinación del torneado y del vaciado fue frecuente en la fabricación de este tipo de piezas (Pugsley, 2003: 111). El torno permite que gire sobre sí misma la pieza en la que se trabaja y, mediante un formón y una gubia, se va dando a la madera la forma deseada. El instrumento cortante empleado en el uso del torno recibe el nombre de ferrum, como se constata en determinadas referencias escritas (Virg. Georg., 2, 449) (Ulrich, 2007: 40). El torno empleado en época romana, siguiendo los precedentes de la Edad del Hierro, responde a dos tipos, el manual y con cuerda, para el que se precisa un asistente (Mille, 2004: 20; Feugère, 2004) (fig. 5). Después, se procede en el propio torno al alisado de la superficie exterior para finalizar el trabajo, untando la pieza con aceites que cerraban los poros y dejándola secar. Desconocemos los aceites empleados en época romana para estas operaciones y, seguramente, en el futuro los análisis realizados sobre las maderas nos permitirán determinar qué productos se utilizaban. Finalmente se procede al secado, una fase importante del proceso, ya que de no tener cuidado es muy posible que la vasija se fracture una vez ya concluida o a los pocos días. Las dificultades para su datación exacta nos impiden extraer más conclusiones sobre el uso del torneado, pero estas piezas nos informan de que se emplea con total seguridad en Hispania en época altoimperial. Para su uso se seleccionaron maderas duras, que son las más adecuadas para los trabajos de calidad, pues permiten ser lijadas, pulidas y resisten mejor el trabajo del torneado, sin astillarse. Los ejemplares hispanorromanos no son una excepción, pues se conocen cuencos también realizados a torno procedentes de Britannia (Pugsley, 2003), algunos dotados de un pie en la parte inferior, como el hallado en Fishbourne, datado en el año 50 d. C. (Henig y MacGregor, 1996: 98, n. ${ }^{\circ}$ ), en Londres (Wilmott, 1982: fig. 32) o en contextos de la Gallia (Chabal y Feugère, 2005: 164-165, fig. 14) y de Germania (Tegtmeier, 2016: 278, lámina 31.1 y 95). 

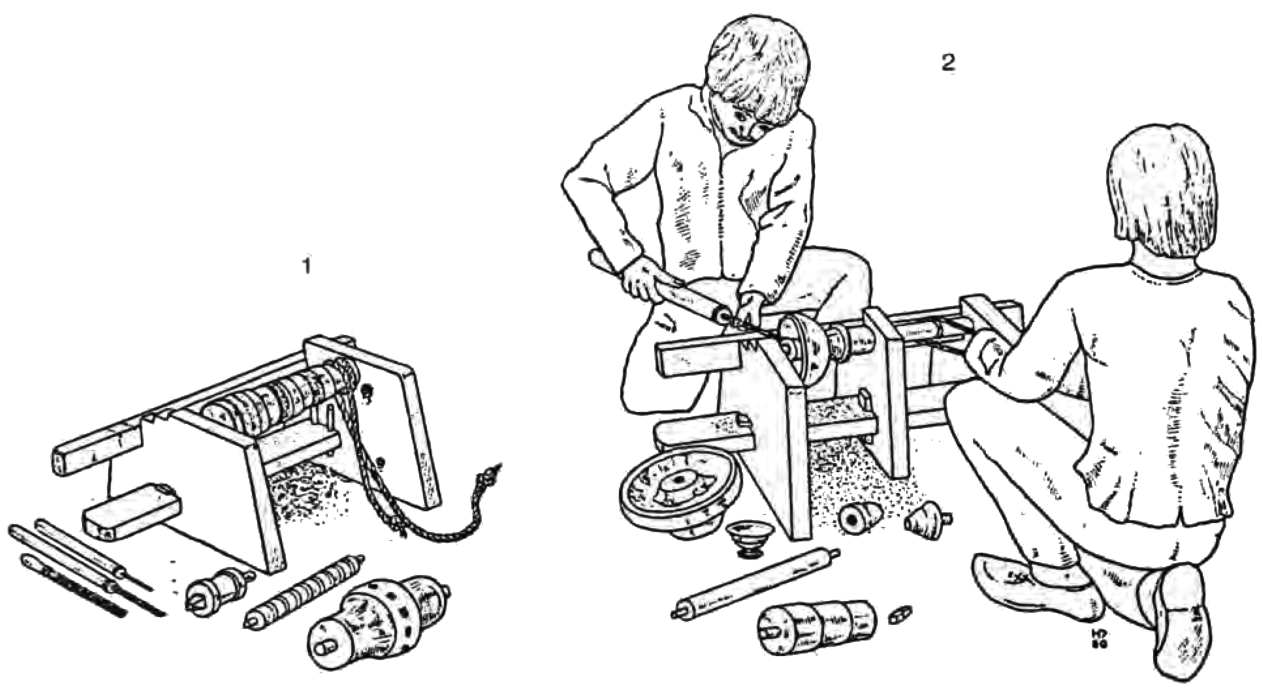

Figura 5. Reconstrucción del empleo del torno de cuerda, que precisa de un asistente para la elaboración de un cuenco, según H. Drescher (extraído de Feugère, 2004: fig. 2).

La selección de las maderas es, por tanto, un proceso importante en la elaboración de las piezas. Aunque no conocemos todas las especies arbóreas con las que se realizaron las vajillas lignarias de Hispania, se realizan cada vez con mayor frecuencia estudios enfocados a determinar la materia prima. Se ha documentado el uso de maderas medianamente duras como el Acer sp. (arce) para el trabajo del cuenco de Iesso (Guissona) y en seis cuencos recuperados en Aquae Flaviae (Chaves, Portugal). Esta es una madera óptima para el uso del torneado, un argumento más que nos permite proponer que el cuenco de Iesso se realizó a torno, lo que explicaría que no cuente con marcas en el exterior y, en cambio, presente una superficie perfectamente pulida. También se empleó una madera semidura como el fresno (Fraxinus sp.) para la elaboración del cuenco de O Areal (Vigo, Pontevedra) y un recipiente de Aquae Flaviae (Chaves, Portugal). El fresno es una madera extremadamente flexible que rara vez se parte; por ello, es ideal para realizar este tipo de objetos curvos y labrados, pues es un material duro, resistente, dúctil y acepta bien el pulimento (Hedinger y Leuzinger, 2003). Por su facilidad en el trabajo, se emplearon también maderas blandas como el Alnus/Corylus (aliso/avellano) en tres recipientes de Aquae Flaviae (Chaves, Portugal), obtenidas de los bosques ribereños más próximos, materia con la que también se fabricaron recipientes de madera en las provincias septentrionales del Imperio (Lucas, 1971: 235-237; Tegtmeier, 2016: 278, lámina 31.1 y 95). En otros dos cuencos se empleó el pino resinero (Pinus pinaster) y pino manso (Pinus pinea). También García y Bellido (1956: 165-166) propone que los recipientes de Iuliobriga pudieron ser realizados con madera de pino, hipótesis difícil de corroborar, porque desconocemos el paradero de las piezas. Aunque estas especies se empleaban generalmente como material de construcción, 
tal y como se ha documentado en Noville (Mugardos, A Coruña) (Martín-Seijo y Carrión Marco, 2012) y en la propia Aquae Flaviae (Chaves, Portugal), se usaron también para elaborar estos recipientes, posiblemente por la facilidad que ofrecen para obtener piezas curvas y sinuosas. Si bien es cierto que se contraen mucho, lo que dificulta su trabajo, son también bastante flexibles y resistentes a la humedad, por lo que se pudo seleccionar este tipo de material en su uso como contenedor de líquidos. La presencia de estas especies se asocia además con la implantación romana; de hecho, en el noroeste peninsular posiblemente fueran cultivadas en este periodo, porque no se documentan hasta este momento (Martín-Seijo, 2019: 189).

La procedencia de la madera con respecto al lugar del árbol de donde se extrae es también un dato importante. Los estudios dendrocronológicos realizados sobre los recipientes de Aquae Flaviae (Chaves, Portugal) determinaron que uno de los recipientes fue fabricado con la madera extraída de un tronco, catorce de ramas y otro de origen indeterminado. En cuanto a la curvatura del anillo de árbol, en dos piezas era muy acusada, en nueve moderada y en cinco menos acusada (Costa et al., 2015: tabla 2), lo que indica que la mayoría se obtuvo de la parte central del tronco, zona de donde se puede extraer un bloque más apto para la fabricación de un cuenco.

Los cuencos hispanorromanos responden a nivel general a dos tipos. Se localizó en Iuliobriga un cuenco con asas perforadas perpendiculares a la pared del recipiente, un tipo que García y Bellido consideró de tradición indígena (1956: 165-166) y que está bien documentado en el norte de Europa, concretamente en Talisker Moor (Skye, Escocia) (Barber, 1982), cuya datación por C-14 confirmó su cronología entre los siglos I-III d. C. Otros cuencos recuperados cuentan con asas horizontales, como los hallados en Killeshall (Tyrone, Irlanda) (Weatherup, 1982: 66 y 70), Bracadale (Skye, Escocia) (Crone, 1993) o Coolnagun (Westmeath, Irlanda) (Lucas, 1971: 235-237).

El resto de recipientes hispanorromanos, de forma cóncava, simple y sin asas, se asemeja más a las piezas localizadas en regiones más romanizadas de Britannia, coincidentes además en cronología, como demuestran los tres ejemplares localizados en diferentes zonas de la ciudad de Luguvalium (Carlisle, Inglaterra), de los que uno se fechó entre los años 70 y 120 d. C., en cronologías coetáneas a la vajilla de mesa de Oiasso (Irún) (figs. 6.3 y 6.5). También se parecen al recipiente de madera de nogal (Juglans regia) hallado en Eboracum (York, Inglaterra), de finales del siglo II d. C., al localizado en Londres, datado entre los años 140 y 160 d. C., o al de Exeter (cf. Earwood, 1991: 278, fig. 131) (fig. 6.1). Se asemejan también a los recipientes de cronología romana localizados en la ciudad romana de Aventicum (Avenches, Suiza) (Pugsley, 2003: 107) y Colonia (Tegtmeier, 2016), así como a los recuperados en el ámbito militar, como evidencian los cuencos de madera del campamento de Birdoswald, de 290-350 d. C., y Vindolanda (Chesterholm), de los años 90 y 140-200 d. C. (cf. Pugsley, 2003: 104-105), así como de los campamentos militares de las provincias renanas de Valkenburg (Países Bajos) (Van Dierendonk et al., 1993: 182-183, n. ${ }^{\circ}$ 4), Saalburg (Baatz, 1998: 72-73) y Nida-Heddernheim (Hampel, 1997), además del vicus militar de Rainau-Buch (Alemania) (cf. Pugsley, 2003: 106). 


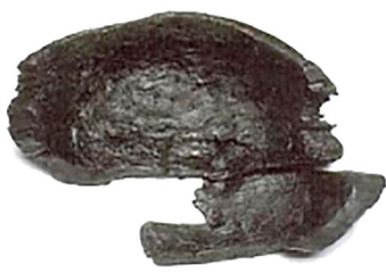

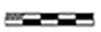



2
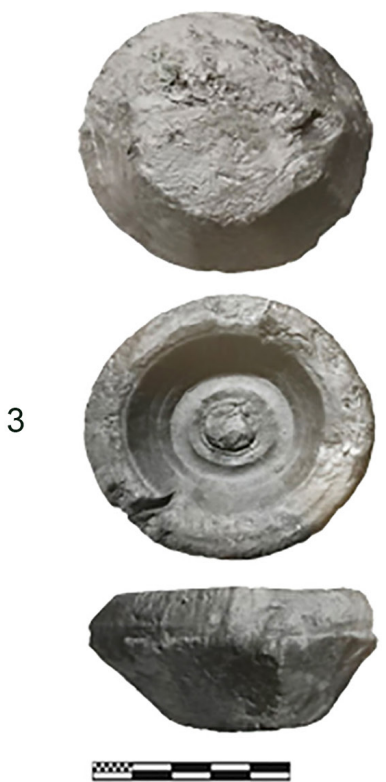

5

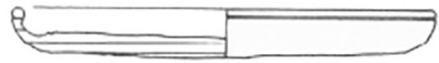

6
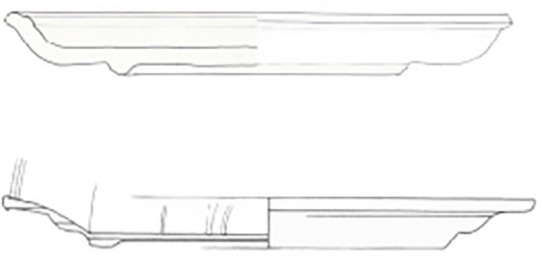

4

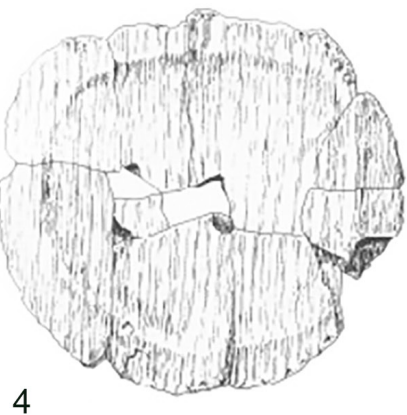

7



Figura 6. Vajilla de madera procedente de contextos del occidente del Imperio romano: 1. Cuenco de madera de Exeter (Earwood, 1991: fig. 131); 2. Bandeja del vicus de Tasgetium (Suiza) (Hedinger y Leuzinger, 2003: 110, n. ${ }^{\circ}$ 73); 3. Cuenco de Colonia (Tegtmeier, 2016: lámina 95); 4. Plato de madera de Carlisle (Inglaterra) (Pugsley, 2003: fig. 5.3); 5. Perfil del plato de la villa romana de Dalton Parlours (Inglaterra) (Morris, 1990: fig. 137.61); 6. Perfil del plato de Carlisle (Inglaterra) (Pugsley, 2003: figs. 5.3 y 7. Perfiles de los platos de madera de Herculano (Pugsley, 2003: fig. 5.4). 


\subsection{Los platos}

El registro arqueológico incluye este tipo de recipientes de madera de formas abiertas, de tendencia plana, forma redonda y borde comúnmente plano. En la península ibérica por el momento son escasos los platos documentados, limitándose a los tres ejemplares recuperados en la excavación del complejo portuario de Oiasso (Irún). En el norte peninsular solamente se han documentado otros dos ejemplares en la Fábrica de Tabacos (Gijón) de época más tardía. El primer ejemplar de Oiasso (Irún) difiere de los otros dos, porque presenta marcas de haber sido tallado y pared recta - una característica derivada del proceso de elaboración- (fig. 7). Los otros dos fueron realizados con el tornus y presentan perfil curvo. Los ejemplares no cuentan con una concavidad en medio y alrededor, como suele ser habitual en los platos lignarios de época romana. El uso del torno para la elaboración de platos está documentado también en dos ejemplares localizados en los yacimientos britanos de
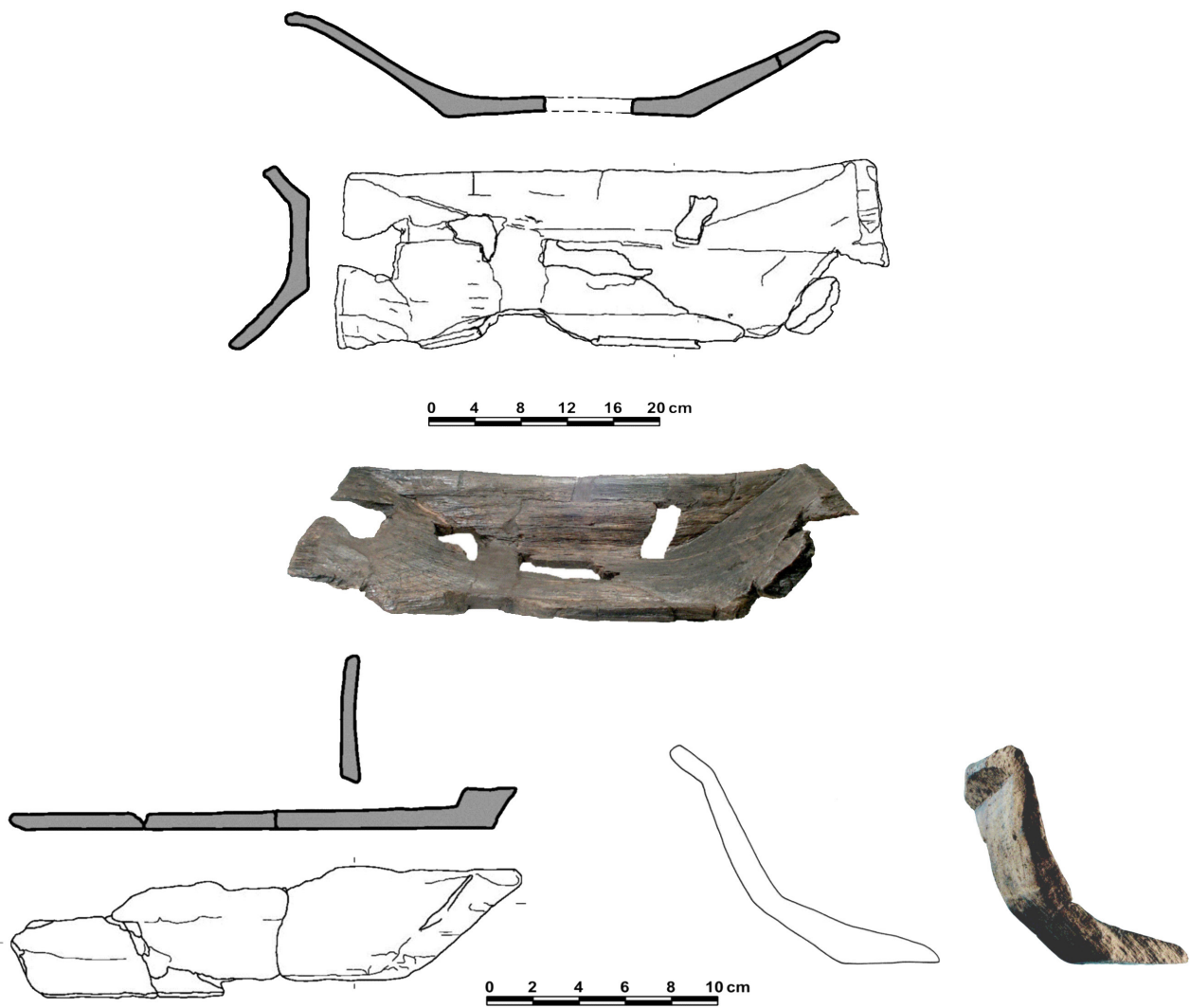

Figura 7. Platos procedentes del complejo portuario de Tadeo Murgia en Oiasso (Irún). Fuente: Urteaga y Alkaín, 2019: 277, figs. 4.17-19. 
Carlisle y Dalton Parlours, realizados con una madera tan dura como el roble (Quercus sp.) (Morris, 1990: 224-225, fig. 137.61; Wrathmell, 1990: 271-272; Pugsley, 2003: 103 y 156). En cambio, es poco frecuente la realización de perforaciones del tercer plato, que quizás servían para colgarlos. Al respecto, podemos destacar el pasaje del Satyricon donde se hace mención a tales recipientes: "Devolvió a la hollinienta pared el clavo que se había caído al descolgar el recipiente de madera (camella lignea)» (Petr. Satyricon, 135).

A tenor de los escasos restos de vajilla de madera de época romana conocidos hasta el momento, resulta muy difícil establecer o determinar el tipo y la forma de esta cultura material. No obstante, debemos decir que la mayoría de los platos y fuentes de madera presentan poca calidad en cuanto a su ejecución técnica y el resultado es la fabricación de piezas toscas. A nivel general debieron imitar la vajilla fabricada en cerámica, pues no parece que tuvieran como referente la forma, proporción y tipología de los platos de metal. Tal es el caso del segundo plato de Oiasso que, en opinión de Urteaga y Alkaín (2019), corresponde a una copia en madera de la forma $5 \mathrm{~J}$ de platos de cerámica común. No obstante, se han reconocido algunos servicios de mesa similares a la vajilla de metal, como el plato de madera de roble aparecido en Stanwick (North Yorkshire, Inglaterra), de fondo plano, y fechado en el siglo I d. C. (Wheeler, 1952: 12), que imita la vajilla de bronce de épocas precedentes. Earwood llamó la atención sobre su similitud con el encontrado en una tumba de La Tène III en Welwyn Garden City (Hertfordshire, Inglaterra) (Stead, 1967: 26-27; Earwood, 1993: 52). La diferencia entre ambas vajillas estriba en la calidad técnica empleada durante su fabricación: los lados del plato de bronce son más verticales y finos que los del plato de Stanwick.

Las dimensiones de los platos de Oiasso (Irún), en torno a $28 \mathrm{~cm}$ y fondo de $14-15 \mathrm{~cm}$, los asemejan a otros documentados en Britannia, como el aparecido en Carlisle (Inglaterra), datado en los años 80 y 105 d. C., con un diámetro máximo de 23,5 cm (Pugsley, 2003: 103 y 156), y al localizado en el interior de un pozo (n. ${ }^{\circ}$ l) del establecimiento rural de Dalton Parlours, de 22,8 cm de longitud y 14 de anchura, datado en el siglo I d. C. (Morris, 1990: 224-225, fig. 137.61) (fig. 6.4), así como al plato de buena factura recuperado en el pecio del Fortuna Maris (Italia) (Berti, 1990: 252, n. ${ }^{\circ} 212$ ), aunque este de dimensiones menores.

Respecto a la calidad de las piezas, los platos de Oiasso (Irún) no alcanzan el grado de acabado y perfección que presenta el plato del Fortuna Maris, con borde afilado y moldeado y pie anular, fabricado con madera de arce (Acer $s p$.), o los tres ejemplares de Herculano (Rieth, 1940a: 631, 1940b: 100) (fig. 6.6). Muy posiblemente estos formarían parte de la vajilla de mesa aristocrática; incluso parecen ser demasiado elaborados como para ser clasificados como simples objetos utilitarios.

\subsection{Las bandejas (lanx)}

Los ejemplares de bandejas en el mundo romano son muy escasos. Es posible que el estado fragmentario en que se suelen conservar haya desembocado en una incorrecta identifica- 
ción de la vajilla, siendo considerados como platos. Por el momento en Hispania solamente se ha documentado la bandeja de la villa romana de Quintanilla de la Cueza (Palencia), que presenta forma ovalada y mide aproximadamente $31 \times 12,5 \mathrm{~cm}$. El trabajo empleado en el ejemplar hispano es poco cuidado y no presenta asas, como la bandeja realizada con madera de olmo (Ulmus sp.) localizada en el vicus de Tasgetium (Eschenz, Suiza), de unos $52 \times 28 \mathrm{~cm}$ y con una anchura de las paredes de 1,5-2 cm (Jauch, 1997: 223, n. ${ }^{\circ}$ 849; Hedinger y Leuzinger, 2003: 110, n. ${ }^{\circ}$ 73) (fig. 6.2).

\section{Consideraciones finales}

El ambiente anaeróbico de determinados contextos del norte peninsular ha preservado los fragmentos de 32 piezas de vajilla de madera que corresponden a recipientes, vasos y cuencos, además de platos y bandejas. Aunque los testimonios son escasos, el conjunto de vajilla lignaria localizado en Hispania es por el momento el más destacado de las provincias romanas del occidente del Imperio. Por otro lado, su estudio nos permite extraer conclusiones sobre las técnicas empleadas en su fabricación, ya sea por las marcas que nos informan sobre su tallado con el trabajo de buril o formón o por las trazas efectuadas mediante el uso del torno.

La participación de los tornatores en la cadena operativa en su elaboración son ilustrativos de la importancia que estas piezas debían tener en la mesa romana. En las piezas peninsulares, aunque a priori parece que se trata de piezas utilitarias, el uso del torno para su elaboración y su similitud con otros hallazgos europeos nos deberían llamar la atención sobre su empleo también en las mesas aristocráticas como vajilla auxiliar de otra más lujosa y refinada.

No cabe duda de que muchas preguntas de momento pueden seguir sin respuesta, pero este estudio pretende poner el foco de atención sobre unas producciones poco perceptibles en el registro arqueológico, además de ofrecer algunas posibilidades interpretativas sobre una línea de investigación que continuará en los años venideros. 


\section{Bibliografía}

\author{
ARANEGUI GASCÓ, C., 1982, Excavaciones en \\ el Grau Vell (Sagunto, Valencia): campañas de 1974 \\ y 1976, Serie de Trabajos Varios 72, Servicio \\ de Investigación Prehistórica, Valencia.
}

BAATZ, D., 1998, Römische Holzgefässe der Saalburg, Saalburg Jahrbuch 49, 66-75.

BALIL, A., 1980, Sobre el uso de vasijas de madera en el mundo romano, Gallaecia 6 , 257-258.

BARBER, J. W., 1982, A wooden bowl from Talisker Moor, Skye, PSAS (Proceedings of the Society of Antiquaries of Scotland) 112, 578-579.

BÉMONT, C., LAHANIER, C. Y JEANLIN, M., 1993, Les figurines en terre cuite gallo-romaines, Documents d'Archéologie Française 38, Université de Bourgogne, Centre de Recherches sur les Techniques Gréco-Romaines, Dijon.

BENAVIDES GARCÍA, R., 2010, Conservación de materiais orgánicos empapados das salinas romanas de Rosalía de Castro II, Vigo (Pontevedra), Actuacións Arqueolóxicas Ano 2008, 351-353.

BERTI, F., 1990, Fortuna Maris: la nave romana di Comacchio, Nuova Alfa, Bologna.

BUXÓ, R., CANAL, D., GUITART, J., PERA, J. y PIQUÉ, R., 2004, Excavació de dos pous d'època romana a Guissona. L'explotació dels recursos vegetals a la ciutat de Iesso als segles I a. C. - II d. C., en J. GUITART y J. PERA (eds.), Iesso I: miscel-lània arqueològica, Barcelona-Guissona, 213-277.

CARBALLO ARCEO, L. X. y FÁBREGAS

VALCARCE, R., 1991, Dataciones de Carbono-14 para castros del Noroeste peninsular, Archivo Español de Arqueología 64/163-164, 244-264.

CARNEIRO, S. y LOPES, R., 2014, Terra Sigillata hispânica tardia dos níveis selados das termas medicinais romanas de Chaves, en R. MORAIS, A. FERNÁNDEZ y M. J. SOUSA (eds.), As Produções Cerâmicas de Imitaçâo na Hispania, Monografias Ex Officina Hispana II, tomo I, Oporto, 549-560.
CARRIÓN, Y. y ROSSER, P., 2010, Revealing Iberian woodcraft: conserved wooden artefacts from south-east Spain, Antiquity 84/325, 747-764.

CASTRO CARRERA, J. C., PRIETO ROBLES, S., SARTAL LORENZO, M., ACUÑA PIÑEIRO, A., IGLESIAS DARRIBA, M. J., RODRÍGUEZ SÁIZ, E., TALLÓN ARMADA, R. y FERNÁNDEZ FERNÁNDEZ, A., 2019, La salina romana de evaporación solar de O Areal - Vigo (Galicia, España). Un ejemplo de arquitectura "efímera» conservada, en A. MORILLO, M. HERMANNS y J. SALIDO (eds.), Ephemeral Archaeology. Products and perishable materials in the archaeological record of Roman times, Nünnerich - Asmus Verlag, Maguncia, 127-142.

CHABAL, L. y FEUGÈRE, M., 2005, Le mobilier organique des puits antiques et autres contextes humides de Lattara, Lattara 18, 137-188.

COSTA VAZ, F., MARTÍN-SEIJO, M., CARNEIRO, S. y TERESO, J. P., 2015, Waterlogged plant remains from the Roman healing spa of Aquae Flaviae (Chaves, Portugal): Utilitarian objects, timber, fruits and seeds, Quaternary International XXX, 1-18. Disponible en <http://dx.doi. org/10.1016/j.quaint.2015.09.063>.

CRONE, B. A., 1993, A wooden bowl from Loch a 'Ghlinne Bhig, Bracadale, Skye, PSAS (Proceedings of the Society of Antiquaries of Scotland) 123, 269-275.

CRONYN, J. M., 1990, Elements of Archaeological Conservation, Routledge, Londres.

DE BLAS CORTINA, M. A., 1995, Vasos de madera y vasos cerámicos: un probable origen romano de ciertas formas en las vajillas de madera de la tornería tradicional, BSAA (Boletín del Seminario de Estudios de Arte y Arqueología) 61, 174-183.

EARWOOD, C., 1989, Radiocarbon dating of late prehistoric wooden vessels, Journal of Irish Archaeology 5, 37-44.

EARWOOD, C., 1991, Wooden objects, en N. HOLBROOK, P. T. BIDWELL Y L. ALLASON- 
JONES (eds.), Roman finds from Exeter, Archaeological Report 5, University of Exeter Press, Exeter, 275-278.

EARWOOD, C., 1993, Domestic wooden artefacts in Britain and Ireland from neolithic to Viking times, University of Exeter Press, Exeter.

FERNÁNDEZ OCHOA, C., SALIDO DOMÍNGUEZ, J., GARCÍA DÍAZ, P. y GIL SENDINO, F., 2015, El uso de la madera en el periodo tardoantiguo: objetos de la vida cotidiana procedentes de la excavación de la Fábrica de Tabacos de Gijón (Asturias), Zephyrus 76, 141-158.

FERNÁNDEZ OCHOA, C., GIL SENDINO, F. y SALIDO DOMÍNGUEZ, J., 2016, Estudio de los materiales arqueológicos, en C. FERNÁNDEZ OCHOA, A. OREJAS SACO DEL VALLE, P. GARCÍA DÍAZ y F. GIL SENDINO (eds.), La Fábrica de Tabacos de Gijón. Arqueología e Historia de un espacio milenario, Ayuntamiento de Gijón, Gijón, 122-153.

FERNÁNDEZ OCHOA, C. y OREJAS SACO DEL VALLE, A., 2019, Las excavaciones del edificio de la Antigua Fábrica de Tabacos (Gijón, Asturias, España): los materiales orgánicos, en A. MORILLO, M. HERMANNS y J. SALIDO (eds.), Ephemeral Archaeology. Products and perishable materials in the archaeological record of Roman times, Nünnerich-Asmus Verlag, Maguncia, 143-160.

FEUGÈRE, M., 2004, Le tournage : une technique, une histoire, un colloque, en M. FEUGÈRE y J.-C. GÉROLD (dirs.), Le tournage, des origines à l'an Mil, Actes du colloque de Niederbronn, Monographies. Instrumentum 27, Editions Monique Mergoil, Montagnac, 9-16.

FIGUEIRAL, I., POMARÈDES, H., COURT-PICON, M., BOUBY, L., TARDY, C. y TERRAL, J.-F., 2015, New insights into Mediterranean Gallo-Roman farming: a closer look at archaeological wells in Southern France, Archaeological and Anthropological Sciences 7, 201-233.

GARCÍA GUINEA, M. A., 2000, Los mosaicos de Quintanilla de la Cueza, La villa romana de Quintanilla de la Cueza (Palencia): memoria de las excavaciones 1970-1981, Junta de Castilla y León, Salamanca, 221-302.
GARCÍA Y BELLIDO, A., 1956, Excavaciones en Iuliobriga y exploraciones en Cantabria (campañas de 1953 a 1956), Archivo Español de Arqueología 29, 131-199.

GEA GARCíA, A. y DÁVILA BUITRÓN, C., 2019, Los materiales orgánicos en el contexto arqueológico: problemas de conservación y protocolo de actuación, en A. MORILLO, M. HERMANNS y J. SALIDO (eds.), Ephemeral Archaeology. Products and perishable materials in the archaeological record of Roman times, NünnerichAsmus Verlag, Maguncia, 51-66.

HAMPEL, A., 1997, Archäologie in Frankfurt am Main. Fund- und Grabungsberichte für die Jahre 1992 bis Ende 1996, Beiträge zum Denkmalschutz in Frankfurt am Main 9, Fráncfort del Meno.

HEDINGER, B. y LEUZINGER, U., 2003, Tabula Rasa. Holzgegenstände aus den römischen Siedlungen Vitudurum und Tasgetium (Schweiz), Documents du Musée Romain d'Avenches 9, Hube, Avenches.

HEINRICH HERMANNS, M., 2019, La madera en los contextos arqueológicos subacuáticos: el caso de la Península Ibérica, en A. MORILLO, M. HERMANNS y J. SALIDO (eds.), Ephemeral Archaeology. Products and perishable materials in the archaeological record of Roman times, NünnerichAsmus Verlag, Maguncia, 161-178.

JAUCH, V., 1997, Eschenz-Tasgetium. Römische Abwasserkanäle und Latrinen, Archäologie im Thurgau 5, Departement für Erziehung und Kultur des Kantons Thurgau, Frauenfeld.

LUCAS, A. T., 1971, Archaeological acquisitions in the year 1968, Journal of the Royal Society of Antiquaries of Ireland 101, 184-244.

MARLIÈRE, É., 2002, L'outre et le tonneau dans l'Occident romain, Monographies Instrumentum 22, Editions Monique Mergoil, Montagnac.

MARLIÈRE, E., 2019, El odre y el tonel en época romana. Testimonios arqueológicos e iconográficos, en A. MORILLO, M. HERMANNS y J. SALIDO (eds.), Ephemeral Archaeology. Products and perishable materials in the archaeological record of Roman times, Nünnerich-Asmus Verlag, Maguncia, 67-78. 
MARTÍN GUTIÉRREZ, M. C., 2000, Industria ósea y otros materiales, en M. A. García Guinea (dir.), La villa romana de Quintanilla de la Cueza (Palencia): memoria de las excavaciones 1970-1981, Junta de Castilla y León, Salamanca, 201-210.

MARTÍN-SEIJO, M., 2019, Madera y sal: estructuras y objetos de madera recuperados en las salinas romanas de O Areal (Vigo, Galicia), en A. MORILLO, M. HERMANNS y J. SALIDO (eds.), Ephemeral Archaeology. Products and perishable materials in the archaeological record of Roman times, Nünnerich-Asmus Verlag, Maguncia, 179-192.

MATTERNE, V. y DERREUMAUX, M., 2008, A Franco-Italian investigation of funerary rituals in the Roman world, «les rites et la mort à Pompéi», the plant part: a preliminary report, Vegetation History and Archaeobotany 17, 105-112.

MILLE, P., 2004, Inventaire des différents types de tours utilisés en Europe occidentale, des origines à l'époque médiévale, d'après la documentation textuelle, archéologique et iconographique, en $\mathrm{M}$. FEUGÈRE y J.-C. GÉROLD (dirs.), Le tournage, des origines à l'an Mil. Actes du colloque de Niederbronn, Monogr. Instrumentum 27, Editions Monique Mergoil, Montagnac, 17-26.

MORENO-LARRAZABAL, A., URTEAGA ARTIGAS, M. y ZAPATA PEÑA, L., 2011, Identification of archaeological wood remains from the roman mine of Arditurri 3 (Oiartzun, Basque Country), Saguntum n. ${ }^{\circ}$ extra 11, 159-160.

MORILLO, A., HERMANNS, M. y SALIDO, J. (eds.), 2019, Ephemeral Archaeology. Products and perishable materials in the archaeological record of Roman times, Nünnerich-Asmus Verlag, Maguncia.

MORRIS, C. A., 1990, Wooden finds, en S. WRATHMELL y A. NICHOLSON (eds.), Dalton Parlours. Iron Age Settlement and Roman Villa, Norfolk, 206-231.

PERA ISERN, J. y GUITART DURÁN, J., 2019, Explotación de los recursos vegetales en la ciudad romana de Iesso (Guissona, Lérida) en los siglos II a. C. - I d. C., en A. MORILLO, M. HERMANNS y J. SALIDO (eds.), Ephemeral Archaeology. Products and perishable materials in the archaeological record of Roman times, Nünnerich-Asmus Verlag, Maguncia, 215-230.
PÉREZ MACÍAS, J. A. y DELGADO DOMÍNGUEZ, A., 2019, Materiales perecederos en las minas romanas de Hispania, en A. MORILLO, M. HERMANNS y J. SALIDO (eds.), Ephemeral Archaeology. Products and perishable materials in the archaeological record of Roman times, Nünnerich Asmus Verlag, Maguncia, 231-248.

POCIÑA, A. y POCIÑA, C. A., 1992, Recipientes griegos y romanos en las comedias de Plauto, Florentia Iliberritana 3, 541-559.

PUGSLEY, P., 2003, Roman domestic wood: Analysis of the morphology, manufacture and use of selected categories of domestic wooden artefacts with particular reference to the material from Roman Britain, British Archaeological Reports, Int. Ser. 1118, Oxford.

RIETH, A., 1940a, Entwicklung der Drechseltechnik, Archäologische Anzeiger 55, 616-634.

RIETH, A., 1940b, Zur technik antiker und prähistorischer Kunst: das Holzdrechseln, IPEK Jahrbuch für prähistorische und ethnographische Kunst 13-14, 85-107.

SADA, P., 2004, Tàrraco i l'aigua, Museu Nacional Arqueològic, Tarragona.

STEAD, I. M., 1967, A La Tène III burial at Welwyn Garden City, Archaeologia 101, 1-62.

STUDER, G., 2003, Método de extracción de los materiales hallados en el puerto de Irún (Oiasso), Monte Buciero 9, 459-467.

TEGTMEIER, U., 2016, Holzobjekte und Holzhandwerk im römischen Köln, Monographien zur Archäologie in Köln, Band 1, NünnerichAsmus Verlag \& Media, Colonia.

ULRICH, R. B., 2007, Roman woodworking, Yale University Press, New Haven.

UNGER, A., SCHNIEWIND, A. y UNGER, W., 2001, Conservation of wood artifacts: a handbook, Springer, Berlín-Londres.

URTEAGA ARTIGAS, M., 2003, El puerto romano de «Oiasso» (Irún) y la desembocadura del río Bidasoa, en C. FERNÁNDEZ OCHOA (ed.), Gijón, puerto romano: navegación y comercio en el Cantábrico durante la antigüedad, Ayuntamiento de Gijón, Gijón, 192-211. 
URTEAGA, M. y ALKAIN CALZADO, P., 2019, Calzado, tejido y otras colecciones orgánicas en Oiasso (Irun), en A. MORILLO, M. HERMANNS y J. SALIDO (eds.), Ephemeral Archaeology. Products and perishable materials in the archaeological record of Roman times, Nünnerich-Asmus Verlag, Maguncia, 263-280.

VAN DIERENDONK, R. M., HALLEWAS, D. P. Y WAUGH, K. E., 1993, The Valkenburg excavations 1985-1988: introduction and detailed studies, ROB, Amersfoort.

VATIN, C., 1972, Wooden sculpture from GalloRoman Auvergne, Antiquity 46, 39-42.

WEATHERUP, D. R. M., 1978, Armagh County Museum archaeological acquisitions 1935-1959, Journal of the Royal Society of Antiquaries of Ireland 108, 23-50.
WEATHERUP, D. R. M., 1982., Armagh County Museum archaeological acquisitions, Journal of the Royal Society of Antiquaries of Ireland 112, 51-71.

WHEELER, R. E. M., 1952, The Stanwick Excavations, 1951. Interim Report, The Antiquaries Journal 32/1-2, 1-13.

WILMOTT, T., 1982, Excavations at Queen Street, City of London, 1953 and 1960, and Roman timber-lined wells in London, Transactions of the London and Middlesex Archaeological Society 33, 1-78.

WRATHMELL, S., 1990, Discussion of Well 1 and its contents, en S. WRATHMELL y A. NICHOLSON (eds.), Dalton Parlours. Iron Age Settlement and Roman Villa, West Yorkshire Archaeology Service, Wakefield, 271-272. 
